\title{
NOTAS SOBRE A EXEGESE DE MITOS EM PLUTARCO
}

\author{
Loraine Oliveira ${ }^{*}$
}

RESUMO: Cet article interroge certains aspects des théories de Plutarque de Cheronée concernant l'interprétation des mythes, tels que sa critique des allégories physiques, d'origine stö̈cienne, et les éléments que définit l'exégèse mystérique des mythes. Nous favorisons donc l'analyse de la position de Plutarque face aux allégories physiques. Dans le De Iside, Plutarque les refuse quand elles sont utilisées isolement en raison de leur incapacité à expliquer précisément la signification des mythes. Mais pour comprendre le fondement de sa pratique exégétiques, il nous faut observer que, pour Plutarque, la philosophie est vue comme initiation. C'est-à-dire, dans sa partie la plus haute, l'époptique, la philosophie permet la connaissance du monde intelligible. Cependant on peut s'étendre sur l'exégèse mystérique des mythes où Plutarque dépasse les limites des allégories physiques. Il mélange dans son exégèse des éléments venus des rites mystériques, de la religion égyptienne et de la philosophie platonicienne et néopythagoricienne.

PALAVRAS-CHAVE: Plutarco, Mito, Alegoria, Mistério, Exegese, Filosofia.

A importância de Plutarco na história da interpretação de mitos é significativa, pois com ele verifica-se que os mitos são cada vez mais associados aos mistérios, e essa associação reflete-se no uso de novos termos técnicos para designar tal procedimento exegético. É a partir de Plutarco que se compreende a substituição do vocábulo

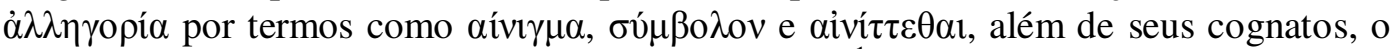
que afinal indica a associação dos mitos aos mistérios ${ }^{1}$. Tal mudança parece representar a passagem dos tipos estóicos de alegoria para os tipos neoplatônicos. O modelo de exegese proposto, então, por Plutarco considera os mitos como imagens do lógos, que refletem nosso pensamento em direção a outra ordem de realidade. A presente investigação tem em De Iside et Osiride a principal fonte, por ser onde florescem termos técnicos e declarações de método acerca da exegese de mitos. Mas subsidiariamente também se recorre a De Pythiae oraculis e, em menor escala, a outros textos que compõem o conjunto denominado Moralia ${ }^{2}$.

\section{A POSIÇÃO DE PLUTARCO FACE ÀS ALEGORIAS FÍSICAS.}

\footnotetext{
Professora do Departamento de Filosofia da Universidade de Brasília (UNB).

Sabe-se que Plutarco e sua esposa eram iniciados nos mistérios de Dioniso (Consolatio ad uxorem, 10, Moralia, 611 d 6 10). Mas, nos limites deste estudo, não será possível investigar a relação de Plutarco com a religião, embora esta seja mencionada em alguns momentos.

As obras de Plutarco são referidas em rodapé com seus títulos latinos, indicando sempre a numeração do texto em questão e sua correspondente em Moralia.
}

Organon, Porto Alegre, no 49, julho-dezembro, 2010, p.155 - 167 
Em Plutarco são raras as ocorrências do termo grego alegoria. O substantivo $\dot{\alpha} \lambda \lambda \eta \gamma$ opía ocorre apenas duas vezes ${ }^{3}$, e outras três vezes encontra-se o verbo

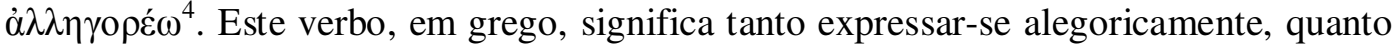
interpretar alegoricamente. O substantivo $\dot{\alpha} \lambda \lambda \eta \gamma$ pí $\alpha$, por sua vez, é formado por $\alpha \lambda \lambda$ os, "outro", e $\alpha \gamma$ $\gamma \varepsilon \varepsilon v \omega$, "falo". Quer dizer, ao se falar de uma coisa, fala-se de outra coisa. Em outros termos, no mundo Antigo, alegoria pode ser definida como a figura de linguagem na qual há um sentido aparente e um outro oculto por trás do aparente. Mas também pode ser entendida como o procedimento hermenêutico que visa descobrir o sentido oculto dos mitos, considerado o verdadeiro. Na Antiguidade o uso da alegoria foi diverso, variando em cada autor, não somente de acordo com a escola ou tendência, mas também ao longo do tempo. Além disso, nem tudo o que foi chamado de alegoria é obrigatoriamente alegórico, nem tampouco todos os procedimentos alegóricos receberam este nome. Donde certa incompreensão do que é essencial na alegoria (Goulet, 2005) ${ }^{5}$. Para compreender a postura de Plutarco é mister notar que ele está familiarizado com as diferentes tendências exegéticas da sua época, e notadamente com as exegeses alegóricas físicas, tal como os estóicos praticavam (Froidefond, 1988, p. $68)$.

Com efeito, as atestações mais antigas do termo alegoria parecem remontar ao século I a.C., mas a palavra $\alpha \lambda \lambda \eta \gamma$ pía pode ter sido difundida a partir da escola de Pérgamo, embora isso não se possa afirmar com certeza. Sabe-se, porém, que na escola de Pérgamo não era praticada uma exegese literal dos textos, mas sim inspirada nas doutrinas estóicas, o que pode ser considerado um dos fatores que abriu a via para os métodos neoplatônico e cristão de interpretação de textos míticos (Hadot, 2005, p. 38 e 478) ${ }^{6}$. A figura principal dessa escola foi Crates de Malos. Simpático ao estoicismo, Crates parece ter encontrado celebridade como crítico de Homero ${ }^{\dagger}$. Via de regra, Crates interpretava em termos físicos as figuras divinas homéricas. Parece que, para Crates, Homero teria tido a intenção de instruir o leitor acerca do cosmos através da alegoria ${ }^{8}$. Crates também se ocupou com outros poetas, dentre os quais Hesíodo, os órficos, Eurípides, Aristófanes, Píndaro. Todavia, seu principal interesse parece ter sido Homero, a quem aplicou os conceitos de antiguidade e da proximidade com a verdade, diferente de Eurípides, por exemplo, que segundo Crates adquiriu seu saber com a cultura (Ramelli, 2003, p. 478).

Ora, Plutarco conhece o tipo de interpretação praticada por Crates ${ }^{9}$ e provavelmente também por outros exegetas de linhagem estóica ${ }^{10}$. Conhece igualmente o uso do vocábulo alegoria tal como possivelmente era empregado a partir da escola de Pérgamo. Todavia Plutarco recusa o tipo de alegoria física praticada por Crates e, de modo geral, opõe-se a diversas formas de alegoria física. Em uma passagem

\footnotetext{
3 Plutarco, De aud. poet., 4, Moralia, 19; De Phytiae Oraculis 30, Moralia 409 d 2.

Plutarco, De Iside 28, Moralia 362 b 1; De Iside 32, Moralia 363 d 5; De esu carnium, I, 13 Moralia 996 b 10.

Os traços característicos da alegoria aqui apresentados nada mais são do que um resumo da caracterização da alegoria por Goulet no artigo referido.

Outros fatores são a prática do comentário filosófico, a influência, cada vez mais determinante, de preocupações religiosas na filosofia e o estabelecimento de interpretações do platonismo associado ao pitagorismo (Brisson, 2004, p. 29).

Diz o Suda k 2342, 1-5: "Crates de Malos, filho de Timócrates, filósofo estóico: denominado Homérico e Crítico, por causa da sua competência acerca de gramática e poética; contemporâneo do gramático Aristarco, próximo (no tempo) de Ptolemeu Filometor, compôs uma Retificação da Ilíada e da Odisséia em nove livros, e outras obras".

Dictionnaire des Philosophes antiques, vol. II, Cratès de Mallos, p. 487 sq. Ver também a entrada de J-M Flamand in Neue Pauly, K. aus Mallos, p. 812

Plutarco menciona Crates no contexto de uma interpretação alegórica, por exemplo, em De facie in orbe lunae, 25 , Moralia, $938 \mathrm{~d}$.

10 Ele menciona explicitamente os estóicos e suas alegorias, por exemplo em De Iside, 40-41, Moralia, 367.
} 
emblemática, Plutarco faz referência à interpretação astronômica do adultério de Afrodite e Ares, e também a uma interpretação física do cinto mágico de Hera, posicionando-se contra tal tipo de exegese:

\begin{abstract}
Estes mitos, alguns comentadores, com o que eles chamavam outrora subentendido ( $\tau \alpha \tilde{\iota} \varsigma$ đó $\lambda \alpha \mathrm{l}$

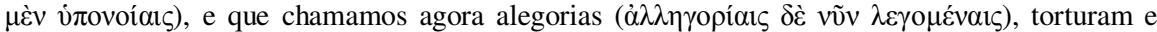
falseiam a interpretação. $\mathrm{O}$ adultério de Afrodite e Ares denunciado por Hélio significa que a conjunção dos planetas Marte e Vênus determina naqueles que nascem sob seu signo, o gosto pelo adultério, e que, se o sol, subindo no céu, os surpreende, estes adúlteros não permanecem ocultos. Quando Hera veste-se em honra a Zeus e recorre a um cinto mágico, querem que se trate na realidade de uma purificação do ar que se aproxima do elemento ígneo, como se o poeta não desse ele próprio uma explicação! (Plutarco, De aud. poet., 4, Moralia, 19) ${ }^{11}$.
\end{abstract}

Esta passagem apresenta um duplo interesse, pois por um lado, Plutarco se mostra testemunho de uma mudança de vocabulário, a substituição de viđovoí $\alpha$ por $\dot{\alpha} \lambda \lambda \eta \gamma o$ pí $\alpha$. E, por outro lado, a passagem apresenta claramente uma crítica à alegoria, que falseia a interpretação. É necessário, contudo, notar que este trecho encontra-se em De audiendis poetis, obra na qual Plutarco parece condenar duramente a alegoria física sob suas diversas formas, o que não ocorre propriamente no De Iside (Froidefond, 1988, p. 87).

Com efeito, no De Iside as alegorias físicas não são totalmente rejeitadas. Plutarco as menciona e, inclusive, serve-se amplamente destas interpretações, como que sobrepondo umas às outras, o que de outro lado, denota sua insuficiência. Por exemplo, Osíris é o Nilo, mas é também o princípio do úmido e é ainda o mundo lunar ${ }^{12}$. Plutarco afirma que tais interpretações tomadas em particular não são exatas, mas no seu conjunto, são justas (De Iside, 45, Moralia, 369 a). Quer dizer, não está em questão estabelecer uma correspondência unívoca entre o elemento divino e o elemento físico. Ao percorrer um conjunto de interpretações físicas, cada uma revela um aspecto diferente da mesma divindade, e isso mostra a insuficiência de cada interpretação tomada isoladamente.

A propósito, deve-se notar que o mito para Plutarco apresenta-se como uma matéria polivalente, pronta para ser utilizada como peça de uma demonstração (Froidefond, 1988, p. 85). De fato, a polivalência alegórica parece ter sido uma prática comum dentre os antigos: era possível atribuir diferentes significados para uma mesma figura mítica, mas também diferentes figuras representavam uma mesma realidade. Destarte, além das alegorias físicas, Plutarco acrescenta também elementos oriundos de diálogos platônicos, como veremos, alargando os significados das figuras do mito de Ísis e Osíris. Em uma declaração de método, ele explica que não devemos nos servir dos

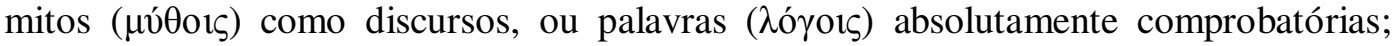
devemos tomar de cada um os traços de semelhança (ó $\mu$ oı́ $\tau\rceil \tau \alpha)$ que se conciliam com nosso pensamento (De Iside, 58, Moralia, 374 e). Em outros termos, a combinação das diversas interpretações resulta no sentido profundo do mito.

Por conseqüência, cabe observar que as críticas de Plutarco a este tipo de exegese alegórica física se voltam contra um certo "imanentismo radical", nas palavras de Froidefond (1988, p. 88). Ele considera que, no contexto do De Iside, as alegorias

\footnotetext{
11 Ver Homero, Odisséia, VIII, 266-369, para o adultério de Afrodite e Ares. Sobre a vestimenta de Hera, ver Ilíada, XIV, 153-189.

12 Plutarco distingue, com efeito, três tipos de alegorias físicas: 1) do tipo meteorológico. Osíris é o Nilo, Isis é o vale do Nilo e Tífon, o mar (De Iside, 32, Moralia, 363 d - 364 a). 2) Do tipo físico, em senso estrito. Osíris é o princípio do úmido, Isis o da terra ávida por água, Tífon o de tudo o que se opõe à umidade (De Iside, 33 - 40, Moralia, 364 a - 367 d). 3 ) Do tipo astronômico. Osíris é o mundo lunar, Isis o mundo terrestre e Tífon, o mundo solar (De Iside, 41 - 44, Moralia, 367 c - 368 f).
} 
estóicas podem ser salvas por pressupostos de caráter teológico, como os do Timeu, os quais ligam as grandes leis do mundo físico ao inteligível. Mas as alegorias seriam estéreis e perigosas se, ao invés de buscar o divino para além do sensível, tencionassem descobri-lo no próprio mundo sensível. Com efeito, ainda que não negue a relação entre os deuses e as realidades físicas, Plutarco pensa que tal relação não deveria ser entendida como sinonímica, mas sim como metonímica - ele exemplifica: “(...) como dizemos daquele que comprou obras de Platão, que ele comprou Platão, e daquele que interpreta as comédias de Menandro, que ele interpreta Menandro" (De Iside, 70, Moralia, $379 \mathrm{a}-\mathrm{b}$ ). O erro de quem pratica as alegorias físicas, por conseguinte, é entender sinonimicamente as relações entre os deuses e as realidades físicas, pois ao serem atribuídas aos deuses as vicissitudes dos elementos físicos, incorre-se em crenças absurdas, perturbadoras e ímpias.

Por fim, nota-se que Plutarco rejeita sem restrições as "alegorias falaciosas" de Evémero de Messina (De Iside, 22-24 Moralia, 359 f -360a), basicamente o acusando de impiedade total, por ter escrito uma mitologia insustentável, na qual os deuses foram substituídos por homens ${ }^{13}$. Para ele, as alegorias evemeristas conduzem ao ateísmo, por reduzirem os deuses à escala humana, e à superstição. A superstição é ainda mais nociva que o ateísmo, pois fornece a ele argumentos contra a religião (De Superstitione, 1, Moralia, 164 e; 6, 167 d-f; 10, 169 f). Entretanto, a melhor forma de escapar aos perigos da superstição e do ateísmo consiste na interpretação filosófica dos mitos e dos rituais concernentes ao culto aos deuses (De Iside, 11, Moralia, 355 d; 71, 379 c-d).

\section{A FILOSOFIA VISTA COMO INICIAÇÃO.}

A posição de Plutarco face à interpretação de mitos está intimamente relacionada à sua concepção de filosofia, vista como um processo de iniciação. Segundo ele, assim como há dois domínios de realidade distintos, o sensível e o inteligível, há dois tipos fundamentais de conhecimento, a física e a teologia, sendo uma subordinada à outra. Ora, o ordenamento do cosmos depende de deus ${ }^{14}$. Por conseguinte, a física, que versa sobre o mundo sensível, não pode dispensar os conhecimentos da teologia. Mas, ao mesmo tempo, o objeto da teologia não pode ser percebido de modo adequado pelo intelecto humano. Logo o conhecimento acessível ao homem é parcial. Aqui se percebe, ainda, a associação entre filosofia e religião, pois o conhecimento do inteligível é identificado ao conhecimento de deus, e este corresponde à forma mais elevada de culto que se pode render à divindade. Portanto, pode-se dizer que o culto se identifica com a filosofia e representa um saber, ainda que inadequado (Zambon, 2002, p. 57). Não por acaso, Plutarco designa a parte da filosofia que se ocupa do inteligível como epóptica, termo oriundo da linguagem dos mistérios, denotando o caráter iniciático deste tipo de

\footnotetext{
13 Evémero viveu pela metade da terceira centúria a.C. e escreveu uma "História Sagrada”, na qual reconstruía a história humana dos deuses gregos, a partir de uma inscrição sagrada que ele teria encontrado na ilha imaginária de Pancaia. Suas alegorias "realistas" fazem de Zeus um rei que tira o poder do seu pai Cronos, e confere ao irmão Posídon o governo das ilhas e províncias marinhas. Um outro exemplo é Afrodite, considerada a primeira cortesã, ela ensinou as mulheres de Chipre a ganharem dinheiro com seu corpo, para não ser a única mulher considerada impudica. Em suma, os deuses para Evémero são considerados homens: reis, legisladores, inventores de técnicas, fundadores de colônias, que teriam vivido num passado muitíssimo distante. Segundo Pépin, Evémero opera uma inversão: a imaginação mitológica resulta sempre de uma encarnação, nunca de uma apoteose. Por exemplo, na zoolatria egípcia, os animais não são divinizados, mas as divindades assumem a forma de animais (Pépin, 1976, p. 57). Afora isso, segundo Sorel (1988, p. 1501), o evemerismo ocupa uma posição dificilmente sustentável: "conferir à mitologia uma certa historicidade é explicá-la por um passado longínquo sem produzir verdadeiramente uma exegese alegórica; é também suprimir o mito sem substituí-lo pela história, recusar o sobrenatural, elaborando um real cientificamente inverificável".

14 Em De Iside, 1, Moralia, 351d Plutarco identifica deus a Zeus, que possui a maior sabedoria e pode comunicá-la aos homens.
} 
conhecimento. Mais precisamente, epóptica designava o mais alto grau de iniciação nos mistérios de Elêusis, ou em geral, os mais altos mistérios, e por extensão significa segredo, oculto ${ }^{15}$.

A partir da interpretação do uso das roupas de Isis e Osíris, Plutarco explica o que vem a ser a epóptica. A indumentária de Isis é policromática, pois o poder da deusa se estende sobre a matéria que recebe todas as formas e sofre todas as vicissitudes. Suas vestes são usadas muitas vezes, uma vez que as coisas materiais são de uso corrente, estão ao nosso alcance, e ao longo de suas mudanças podemos vê-las e tocá-las. A roupa de Osíris, por seu turno, é monocromática, não possuindo sombra, nem variedade. Sua única cor é a da luz. Isso se explica porque o ser primordial é inteligível, não admitindo mistura. A visão do ser inteligível é como um clarão que ilumina nossa alma, e só pode ser obtida uma única vez. Por esse motivo, a vestimenta de Osíris só é usada uma vez, depois é guardada, não sendo mais vista nem tocada (De Iside, 77, Moralia, 382 d). Depois de estabelecidas tais correspondências entre as vestes de Isis e de Osíris e, respectivamente, o mundo material e o inteligível, Plutarco associa definitivamente a filosofia à iniciação:

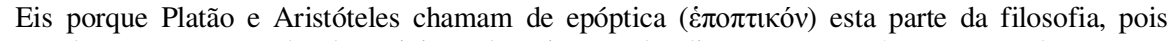
aqueles que, escapando da opinião, da mistura, do diverso, graças à razão, se lançam no primordial, indivisível, imaterial, e entram totalmente em contato com a pura verdade em torno dele, pensam assim ter atingido, como em uma iniciação (oĩov $\dot{\varepsilon} v \tau \varepsilon \lambda \varepsilon \tau \tilde{n} \sim$ ) o fim último da filosofia (De Iside, 77, Moralia, $382 \mathrm{~d}-\mathrm{e})$.

Conforme Zambon (2002, p. 57), esta passagem revela que Plutarco concebe a forma mais alta de conhecimento não somente como um fato intelectual, mas também ético, pois se dá ao termo de uma elevação. Além disso, Platão e Aristóteles são apresentados juntos, isto é, a dialética de um e a teologia de outro são consideradas equivalentes por Plutarco, e ambos passíveis de ser considerados epópticos. Com respeito à exegese de mitos, e também dos símbolos religiosos, a filosofia fornece os critérios racionais e adequados para que não se incorram em erros interpretativos; somente ela é capaz de compreender o significado profundo dos mitos e dos cultos (De Iside, 11, Moralia, 355 b; 20, 358 e; 25, 360 d-e; 32, 363 d; 58, 374 e).

\section{A EXEGESE MISTÉRICA DOS MITOS.}

Plutarco estabelece uma relação entre alegoria e imagem na tentativa de responder ao problema proposto pelas interpretações das respostas oraculares formuladas pela Pítia de Delfos, em nome de Apolo. Tal problema é análogo ao da exegese dos mitos homéricos e hesiódicos, uma vez que tanto em um caso, como em outro, abandona-se o sentido literal para buscar um ensinamento útil, subjacente. Na condição de sacerdote de Apolo em Delfos, Plutarco recebe de bom grado a mudança que marca os oráculos da Pítia à sua época: ela não mais se exprime em forma de poesia e de modo obscuro. Falando através de uma linguagem clara, seus oráculos são acessíveis a todos. Ademais, o abandono da linguagem poética é observado não somente no âmbito da mântica, mas igualmente no domínio da história e da filosofia:

15 Vocábulo que aparece em Platão, Banquete, 210 a, referindo-se aos mistérios do amor. Sob uma certa leitura do

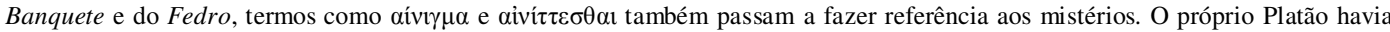
nos referidos diálogos, utilizado o vocabulário dos mistérios, notadamente os de Elêusis, para descrever a experiência filosófica. Donde resulta, para Plutarco, uma assimilação completa entre filosofia e religião. 
A linguagem sofreu a mesma transformação e o mesmo despojamento: a história desceu da poesia como de um carro, e é sobretudo graças à prosa, e indo a pé, que separou a verdade da lenda $(\mu v \theta \omega ́ \delta o \theta \varsigma)$; a filosofia agora prefere clarear e ensinar, mais que fascinar, e só faz suas pesquisas em prosa (Plutarco, De Pythiae oraculis, 24; Moralia, 406 e2-406 e7).

De modo geral, Brisson e Pépin, estudiosos que se ocuparam em traçar a história do mito e sua interpretação na Antiguidade, costumam interpretar essa passagem relativa ao abandono da forma poética, que exigia uma postura alegorista, em paralelo com a adversidade de Plutarco ao estoicismo. Em outras palavras, ao aprovar a nova linguagem da Pítia, Plutarco parece ridicularizar a sobrevivência das alegorias estóicas, que ele considera como sendo pueris. Nesse sentido, Plutarco compara a linguagem enigmática da poesia e dos oráculos aos arco-íris e cometas que fascinam as crianças mais do que o próprio sol ou a lua. São tais mentalidades infantis que lamentam o fim

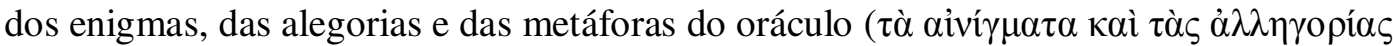

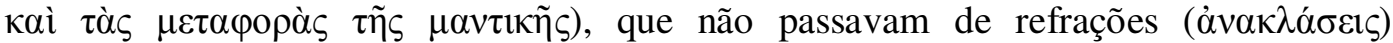
apropriadas à nossa natureza mortal e ávida por imagens. Com efeito, o deus não pode ocultar a verdade, portanto ele a manifesta de modo "desviado" ( $\pi \alpha \rho \alpha \tau \rho \varepsilon ́ \pi \omega v)$, sob a forma da linguagem poética. Esta é comparada ao reflexo de um raio luminoso: o reflexo, assim como a poesia, subtrai o que machuca e é duro. Todavia, Plutarco reconhece que nem tudo é negativo na mântica alegórica: fundamentalmente, a dissimulação da verdade aos indignos foi considerada o maior benefício de toda linguagem alegórica.

Pode-se então compreender o método exegético proposto por Plutarco, que considera os mitos como símbolos, ou ainda, como enigmas que devem ser desvendados pela filosofia. Entende que os mitos possuem uma formulação ambígua e obscura, suscetível de um duplo nível de interpretação de doutrinas profundas. Esta concepção do mito parece remeter aos mistérios, e igualmente ao neo-pitagorismo, cujas doutrinas orais eram qualificadas de símbolo, e o segredo desempenhava um importante papel (Brisson, 1996, p. 98). Plutarco introduz, então, outro vocabulário, que em parte provém da linguagem dos mistérios, para referir-se aos mitos, e por conseqüência, à interpretação dos mesmos ${ }^{16}$. O termo alegoria vê-se substituído por enigma e outros da mesma família. Não obstante, esses termos adquirem um sentido especializado, que não possuíam antes. Com efeito, consoante Brisson (1996, p. 90) "ele pratica uma exegese do tipo metafísica e mistérica (...). Eis porque se pode considerá-lo como o ponto de passagem entre a alegoria do tipo estóico e a alegoria do tipo neoplatônico"17.

No De Iside et Osiride Plutarco estabelece princípios da interpretação de mitos, tendo por fundamento o segredo, que deve ser observado tanto no âmbito da religião, como da filosofia. Ele afirma que o segredo era praticado no Egito, terra que considera fonte de toda civilização. Segundo ele, no Egito, a filosofia estava associada à religião, como pode ser observado em duas formulações que se complementam: (1) a filosofia

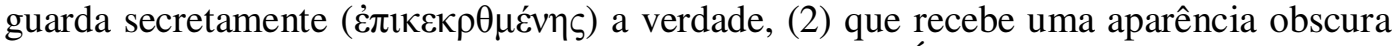

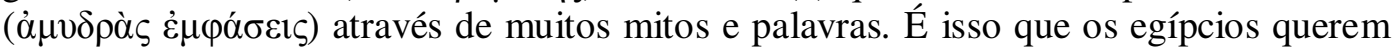
nos fazer compreender erguendo esfinges diante dos templos, indicando assim, que a sabedoria da sua doutrina sagrada ( $\theta \varepsilon \circ \lambda \circ \gamma i ́ \alpha \varsigma)$ tem forma enigmática ( $\alpha i v i \gamma \mu \alpha \tau \omega ́ \delta \eta$ - De Iside, 9, Moralia, $354 \mathrm{~b}-354 \mathrm{c}$ ). Os gregos mais célebres são testemunhos disso;

16 E emblemática a passagem na qual, referindo-se aos gregos mais esclarecidos, mormente a Pitágoras, diz que tentam

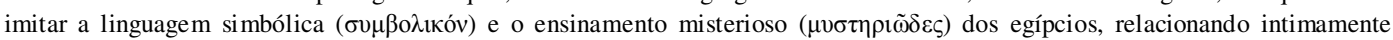

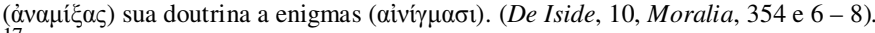
Ver De Iside, 25-26; 45-64, Moralia 360 e - 361 c; 369 a - 377 a. 
Pitágoras é, dentre os referidos gregos, o mais admirado, e o introdutor do segredo na filosofia ${ }^{18}$. Ora, se os mitos têm uma forma enigmática, é preciso decifrá-los. A exegese

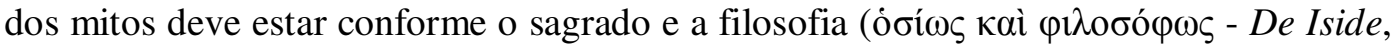
11, Moralia, 355 c).

Assim sendo, ele associa os mitos aos mistérios, servindo-se principalmente do Timeu, mas também do Banquete de Platão, da Teogonia de Hesíodo e do mito órfico do desmembramento de Dioniso, para elaborar sua exegese do mito de Isis e Osíris. O Timeu fornece o panorama filosófico onde todos estes elementos e associações tomam lugar. Plutarco estabelece uma distinção nítida entre uma divindade transcendente e uma matéria totalmente indeterminada. Para dar conta do caos e da irregularidade do movimento que atravessa a natureza corpórea, ele se vê compelido a postular uma alma do mundo inicialmente irracional, que é ordenada, na medida do possível, pela inteligência do demiurgo (Brisson, 1996, p. 92). Quanto a Hesíodo, pode-se dizer resumidamente que os personagens do mito egípcio são substituídos por outros, hesiódicos: Isis é Deméter, a Terra, Osíris é Eros, o amor, e Tífon é o Tártaro (De Iside, 57, Moralia, $374 \mathrm{~b}-\mathrm{c}$ ). Ademais, ele associa o mito egípcio ao mito do nascimento de Eros do Banquete, 203 b - c: Isis é Penia, Osíris é Poros, e Eros, que nasce da união de ambos, é Horus (De Iside, 57, Moralia, 374 c - e). Osíris também é associado a Dioniso, mais precisamente ao mito órfico do desmembramento de Dioniso. Plutarco fundamenta tal associação com os ritos dos mistérios, por exemplo, quando diz que tudo o que se conta do desmembramento de Osíris e do seu retorno à vida, é análogo ao que se comemora nas Nictélias, festas noturnas do solstício de inverno, cujo tema era o mistério da morte e ressurreição de Dioniso (De Iside, 35, Moralia, 364 e - 365 a). Ao permitir-se interpretar o mito egípcio em perspectiva com os mitos de Hesíodo e dos órficos, com a religião dos mistérios dionisíacos, e com a filosofia de Platão, Plutarco mostra-se plenamente consciente dos procedimentos alegóricos de que faz uso. Eis suas palavras: "É preciso, portanto, servir-se dos mitos, não como razões absolutamente

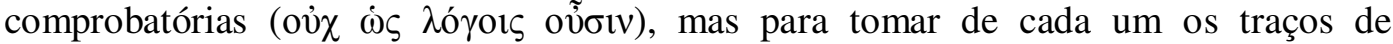
semelhança que se conciliam com nosso pensamento" (De Iside, 58, Moralia, 374 e).

\section{CONSIDERAÇÕES FINAIS}

Como vimos, Plutarco representa um marco fundamental para a história da alegoria antiga. Ele testemunha a passagem de um tipo de interpretação de mitos, que designa por alegoria, para outro, enigmático, mistérico. Mas mais do que isso, ele pratica o tipo de exegese que propõe em seu Sobre Isis e Osíris. E neste opúsculo, Plutarco vai explicando seus procedimentos, o que torna esta uma obra chave para a questão.

Todavia, para terminar este breve estudo, gostaria de retomar uma idéia rapidamente mencionada, que indica um caminho ulterior das minhas pesquisas sobre Plutarco. Trata-se da relação entre mito e imagem, exposta através da metáfora do arcoíris, que na passagem supracitada do De Phytiae Oraculis representa a poesia e a linguagem enigmática dos oráculos, que fascina as mentes infantis, como as refrações da luz do sol. Diz Plutarco que a nossa natureza mortal é ávida por imagens. Pois bem, no De Iside, 20, também há uma alusão ao arco-íris, comparado a um mito. Nesta

$18 \quad$ “(...) eis até onde iam as precauções dos egípcios em matéria de segredo religioso. É o que atestam os maiores espíritos da Grécia, Sólon, Tales, Platão, Eudoxo, Pitágoras, Licurgo também, segundo alguns, que vieram ao Egito e viveram na sociedade dos padres" (De Iside, 10, Moralia, 354 e).

Organon, Porto Alegre, nº 49, julho-dezembro, 2010, p.155 - 167 
passagem, ele diz que o arco-íris é uma imagem do sol, diversamente colorida pelo reflexo dos raios nas nuvens. O mito é como um arco-íris, diz ele, imagem de uma certa verdade que reflete um mesmo pensamento em meios diferentes. É isso que os rituais impregnados de luto e tristeza aparente nos dão a entender. E também os templos, com sua arquitetura que ora deixa livres grandes esplanadas, ora oculta salas onde os deuses são vestidos. Ritos e templos aparecem aqui como representações da imagem refratada da mesma verdade. Em ambos os casos, Plutarco menciona coisas aparentes, coisas ocultas sob a aparência. A tristeza, que é aparente, as salas, que ocultam os deuses. É este o tipo de imagem do mito, enfim. Imagem multicolorida, multirrefratada, encantadora, por sua beleza, como a arquitetura antiga sempre foi considerada, e emocionada, ainda que em aparência. Mas este é, como disse, apenas o começo de um outro aspecto da mesma pesquisa.

\section{BIBLIOGRAFIA}

BRISSON, L. Introduction à la philosophie du mythe 1 - Sauver les mythes. Paris: Vrin, 1996.

"L'allégorie comme interprétation des mythes, de l'Antiquité à la Renaissance". In: PEREZ-JEAN, B.; EICHEK-LOJKINE, P. (études réunies par). L'allégorie de l'Antiquité à la Renaissance. Paris: Honoré Champion, 2004.

CORNUTO. Compendio di Teologia Greca. A cura di I. Ramelli. Milano: Bompiani, 2003.

GOULET, R. "La méthode allégorique chez les stoïciens". In: ROMEYER DHERBEY, G. (dir.) GOURINAT, J.-B. (ed.). Les Stö̈ciens. Paris: Vrin, 2005.

HADOT, I. Arts libéraux et philosophie dans la pensée antique. Contribution à l'histoire de l'éducation et de la culture dans l'Antiquité. Paris: Vrin, 2005.

PÉPIN, J. Mythe et allégorie. Les origines grecques et les contestations judéochrétiennes. Nouvelle édition revue et augmentée. Paris: Études augustiniennes, 1976.

PLUTARCO. Isis y Osiris. Diálogos Píticos. Obras Morales y de Costumbres, v. VI. Introducciones, traducciones y notas por F. P. Pardo y J.A.F. Delgado. Madrid: Gredos, 1995.

Oeuvres morales. Introduction générale par R. Flacelière et J. Irigon; texte établi et traduit par A. Philippon et al. Paris: Les Belles Lettres, 1972.

Oeuvres Morales. Isis e Osiris. Texte établi et traduit par C. Froidefond. Tome V, $2^{\mathrm{a}}$ partie. Paris: Les Belles Lettres, 1988.

. Sur les oracles de la Pythie. Texte établie et traduit par R. Flacelière. Introduction et notes par S. Crippa. Paris: Les Belles Lettres, 2007.

RIEDWEG, C. Mysterionterminologie bei Platon, Philon und Klemens von Alexandrien. Berlin, New York: Walter de Gruyter, 1987.

SOREL, R. "De l'interprétation du mythe". In: JACOB, A. (Dir). Encyclopédie Philosophique Universelle. Vol. IV - Le discours philosophique. Volume dirigé par J.F. Mattéi. Paris: PUF, 1998, p. 1498-1513.

ZAMBON, M. Porphyre et le moyen-platonisme. Paris: Vrin, 2002. 